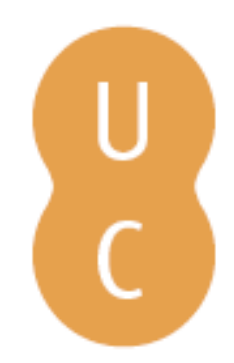

\title{
nombalina
}

\section{La Antígona de María Zambrano o el oficio de la piedad}

Autor(es): Lázaro Paniagua, Alfonso

Publicado por: Centro de Estudos Clássicos e Humanísticos da Universidade de

URL

persistente: URI:http://hdl.handle.net/10316.2/30247

DOI: $\quad$ DOI:http://dx.doi.org/10.14195/978-989-721-038-9_28

Accessed : $\quad$ 26-Apr-2023 10:56:01

A navegação consulta e descarregamento dos títulos inseridos nas Bibliotecas Digitais UC Digitalis, UC Pombalina e UC Impactum, pressupõem a aceitação plena e sem reservas dos Termos e Condições de Uso destas Bibliotecas Digitais, disponíveis em https://digitalis.uc.pt/pt-pt/termos.

Conforme exposto nos referidos Termos e Condições de Uso, o descarregamento de títulos de acesso restrito requer uma licença válida de autorização devendo o utilizador aceder ao(s) documento(s) a partir de um endereço de IP da instituição detentora da supramencionada licença.

Ao utilizador é apenas permitido o descarregamento para uso pessoal, pelo que o emprego do(s) título(s) descarregado(s) para outro fim, designadamente comercial, carece de autorização do respetivo autor ou editor da obra.

Na medida em que todas as obras da UC Digitalis se encontram protegidas pelo Código do Direito de Autor e Direitos Conexos e demais legislação aplicável, toda a cópia, parcial ou total, deste documento, nos casos em que é legalmente admitida, deverá conter ou fazer-se acompanhar por este aviso.

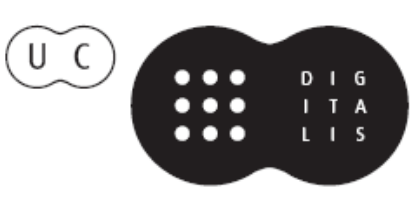




\section{De ayer a hoy}

\section{Influencias clásicas en la literatura}

\section{Aurora López, Andrés Pociña, Maria de Fátima Silva (coords.)}




\section{La $A N T i ́ g O N A$ de María Zambrano o el oficio de la Piedad}

Alfonso Lázaro Paniagua

I.E.S. Luis Bueno Crespo

En este trabajo, centrado en La tumba de Antígona de la filósofa malagueña María Zambrano, se pretende destacar el valor de la tragedia como oficio de la piedad. Asimismo rescatar para la modernidad (en la medida de lo posible) el principio que inspira lo trágico: destino/ libertad.

La Antígona de Zambrano se abre con un soliloquio que es delirio. El delirio mana de una conciencia no reconciliada consigo misma, se manifiesta en el curso errático del desvarío. Las interrogaciones encadenadas así lo manifiestan. Pero el delirio de Antígona tiene una nítida procedencia, ya que se trata del hundimiento de una historia familiar que culmina en la lucha fratricida entre Eteocles y Polinices, sus dos hermanos. Antígona hereda ese hundimiento antes de franquear los umbrales de su autonomía personal y antes de celebrar las prometidas nupcias con Hemón. Antígona queda sin tiempo, petrificada entre el horror de su ascendencia y la privación de toda esperanza. Pero a diferencia de Sófocles, Zambrano no culminará su obra con la muerte de la heroína, pues eso despojaría su protagonismo: el alumbramiento de sentido que lleva la historia familiar y de la polis más allá de su puro hundimiento, de su pura destrucción, porque sobrepasándolos, los rescata. "Antígona, en verdad,- nos dice Zambrano- no se suicidó en su tumba, según Sófocles, incurriendo en un inevitable error nos cuenta", pues entonces, sigue Zambrano "el conflicto trágico no alcanzaría a serlo, a ingresar en la categoría

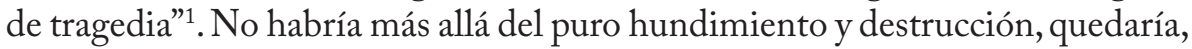
pues, la tragedia detenida en el lamento sin fin y sin finalidad. El lamento de Antígona en los primeros soliloquios de la obra, antes de hacerse anfitriona de las sombras que la visitan, es corrosivamente lúcido: "La desgracia golpeó con su martillo mis sienes hasta pulirlas como el interior de una caracola, hasta que fueron como dos oídos que sentían los pasos blandos de la desdicha, su presencia; esos pasos blandos con que la desdicha mucho antes de desatarse entra en nuestra cámara y viola el recinto del sueño sin mirarnos siquiera. Se presenta y está ahí fija, se queda exhalando terror, un terror que llega a ser como una túnica, ésta, ésta que me pusieron ya de niña, y que ha ido creciendo conmigo hasta ser como mi propia piel"2. Pero Antígona, para Zambrano, no

\footnotetext{
${ }^{1}$ Zambrano, María, p. 41.

${ }^{2}$ Ibid., pp. 45-46.
} 
podía ser el epígono del hundimiento familiar y político, la última víctima de un enloquecido destino que sepulta los acontecimientos y humilla la memoria soldándola a la catástrofe.

Éste es el hecho determinante de la obra de Zambrano, La tumba de Antígona. La heroína no podía morir, porque si así fuese se cerraría el hundimiento de la saga familiar en su propia condena. Antígona habrá de transformar la lucidez que llaga en luciente fármaco que alivia y sana. La tumba de Antígona no se sella conteniendo el cadáver, sino que, entreabierta, deja que se deslicen en su interior las sombras familiares que el delirio de la muchacha va constituyendo a modos de simulacros. Antígona los recibe como huéspedes y ellos, uno a uno, Ismene, Edipo, la nodriza Ana, Yocasta, la arpía, los hermanos, Hemón, Creonte irán revelando honduras de Antígona, dicho de otro modo, despertando su vocación: la vocación-Antígona. Y no será otra cosa esa vocación que la acción de la piedad. De ello hablaremos más adelante, pero ahora tratemos a cada personaje huésped en la intimidad de la anfitriona.

Antígona está en su tumba a medio abrir. En su descenso, la congestión del llanto. Presa de un delirio lúcido que antes hemos señalado, la heroína va fijando diversas sombras en su mente que insensiblemente, debido a la contextura del sueño en que se desenvuelve la escena, se emancipan de su imaginación y se objetivan como fantasmas que dialogan. Con Ismene, la propia Antígona se desdobla y le recuerda lo que ella sola había hecho: "acompañar a nuestro padre, después ir a lavar a nuestro hermano maldecido"3. A continuación le pregunta por Creonte: “¿Todavía está ahí mandando?”, lo que evidencia que la escena discurre en un tiempo indefinido. Los personajes flotan en esa atmósfera de ingravidez propia de los sueños. En ese momento Antígona revela su naturaleza mediadora al autodefinirse como lavandera y asociarse al elemento agua. "Pero no, Ismene, no, hermana. Tú no tenías que venir conmigo a lavar a nuestro hermano sin honra, porque mira, ya está claro, la lavandera soy yo" ${ }^{4}$ La que lava la sangre derramada y la hace correr. Por esto, Antígona se reconoce en su papel, va cayendo de la mentira en que estaba y gana conciencia, es su anagnórisis lo que se despeja en la categoría de tragedia de Zambrano. La conciencia que alumbra Antígona gana peldaños por momentos: “... la sangre no debe quedarse dura como piedra. No, que corra como lo que es la sangre, una fuente, un riachuelo que se traga la tierra. La sangre no es para quedarse hecha piedra, atrayendo a los pájaros de mal agüero, auras tiñosas que vienen a ensuciarse los picos. La sangre, así, trae sangre, llama sangre porque tiene sed, la sangre muerta tiene sed y luego vienen las condenas,

\footnotetext{
${ }^{3}$ Ibid., p. 46.

${ }^{4}$ Ibid., pp. 46-47.
} 
más muertes, todavía más en una procesión sin fin" ${ }^{5}$. El agua disuelve la sangre y la emboca en manantial y fluye con ella su historia, la desenreda, porque en esto es Antígona contundente: “...no me muero, no me puedo morir hasta que no se me dé la razón de esta sangre y se vaya la historia, dejando vivir a la vida"6. He aquí el sentido más revelador de la obra de Zambrano, el oficio de la piedad que es la vocación-Antígona, dar razón de esta sangre, por la historia propia, y por extensión, de toda historia.

Allector u oyente puede sorprenderle la contraposición historia y vida, pero en Zambrano es lo propio. Véase en esta alusión que oye Ismene la distinción y contraposición de ambos conceptos: “... mi historia es sangrienta. Toda, toda la historia está hecha con sangre, toda historia es de sangre, y las lágrimas no se ven"7. Tendremos ocasión de asociar la historia a la ley vieja que representa Creonte, y la vida a la ley nueva que profetiza Antígona. Profetismo que tiene no pocas analogías con Sócrates y su condena, pues en Sócrates puede verse al hombre que se ofrece en sacrificio en aras de la nueva ley de la polis.

Sin que medie intervalo alguno, desaparece por el fondo del sueño Ismene y se impone el fantasma de Edipo, que ya ve, y se ve a sí mismo. Constata su identidad indisoluble de su desdicha: "Mi padre me abandonó. Y fue el pastor quien se compadeció de mí y cambió mi suerte, mi condena a muerte en condena a vivir abandonado. Y yo iba, como una nube suelta, olvidado de mi padre. Y así, dejado, ¿qué iba yo a hacer? Si hubiera sabido, no habría hecho nada, lo que se dice nada, antes de volver a mi casa, a encontrarme con mi padre. Eso, ahora, tan tarde ya, es cuando lo sé" ${ }^{8}$. Con Edipo, Antígona se dispone a despejar lo que su padre le había vedado como resistencia última: su madre. Edipo eludía a Yocasta, su madre, y aludía a ella por un pronombre: "Ella", lo que irrita a Antígona, reprochándole algo así como: ¿por qué me lo ocultabas? La dureza con que Antígona se expresa constituye un momento de máxima lucidez: "Cuando dices que soy cruel, entonces me llamas Antígona. Pero es que sale de mí la verdad una vez más sin culpa mía. Ella, la verdad, se me adelanta. Y yo me la encuentro de vuelta, cayendo sobre mí, la verdad cae siempre sobre mí." Gana la conciencia-Antígona al sentirse al descubierto de todo y de todos. La verdad se experimenta como un peso que detiene y pertrifica, y no como algo que nos mueve por la alegría del descubrimiento. Es una muestra más de la inocencia sacrificada y por él, por el sacrificio que soporta hasta el extremo Antígona habrá de ir desatándose, desenredándose el nudo de la entraña familiar y de la historia de la ciudad. Bien claro se lo dice

\footnotetext{
${ }^{5}$ Ibid., p. 48.

${ }^{6}$ Ibid., p. 48.

${ }^{7}$ Ibid., pp. 52-53.

${ }^{8}$ Ibid., p. 50.

${ }^{9}$ Ibid., p. 49.
} 
Edipo en este encuentro: “Tú eres mi razón”. Aunque esto mismo se lo podría haber dicho a Antígona cualquiera de los personajes que la visitan. Porque extraviados en el error, buscan la salida. Buscan salir de la historia que los tiene apresados: esa es su razón que sólo puede poner en circulación Antígona. Se trata de hacerlos nacer más allá de la pesadilla en que yacen encadenados." ¿Cómo voy a poder hacerlos nacer a todos? Pero sí, yo, yo sí estoy dispuesta. Por mí, sí; por mí, sí. A través de mî” ${ }^{10}$.

Vale la pena detenerse un instante para saber con rigor qué nace de la piedad, el oficio de la tragedia. Mucho debe el conocimiento griego a la idea del alumbramiento. Recuérdese a este respecto no más que la mayeútica socrática. Y entre Antígona y Sócrates se tienden puentes evidentes. También sufrió proceso y condena, en el lenguaje de Zambrano fue sacrificado a los ínferos de la ciudad. Ni Creonte, condenando a Antígona, ni los jueces (Anyto y Melyto) que condenaron a Sócrates supieron ver, tampoco quisieron, el anuncio profético de la nueva ley. La verdad socrática habrá de nacer de las tribulaciones de la reflexión; no es mejor ciudadano el que se deja subyugar por la ley - ley de cualquier forma de poder, de las muchas que subyugan al hombre-, sino el que se vincula reflexivamente a la ciudad. El amor a la polis es indisoluble del esfuerzo compartido (diálogo) por alumbrar la verdad. La verdad nace; no es cosa, pues, de imponerla ante-dicha, como sucede con todo poder que se impone desde el terror. Y no hay que olvidar que el profetismo de la nueva ley es el amor, frente al resorte de la vieja ley que es el terror.

El oficio de comadrona de Antígona habrá de ser muy otro, aunque conservándose ese vínculo que hemos subrayado. El saber no nace de la reflexión, sino del delirio que a su término, en su máxima agudeza estalla con inaudita claridad, claridad nacida del extremo mismo del delirio, cuyo fruto es soledad y libertad, liberando, pues, a cada personaje de ser apéndice de la desdicha que abrasa a toda la estirpe. Liberación que convierte al personaje en persona, liberándole de la máscara que le oprime. No otro es el nacimiento que está tras la súplica de Edipo: "Ayúdame, hija, Antígona, no me dejes en el olvido errando. Ayúdame ahora que voy sabiendo, ayúdame, hija, a nacer"11. Esa mayeútica la refuerza la nueva sombra-huésped que visita la tumba de Antígona cuando el fantasma de Edipo se disuelve tras su súplica. Esa nueva sombra es la nodriza Ana. A ti, niña, "te espera otra cosa mejor que el descanso"12. Ana asocia a Antígona por entero al elemento agua: “...estabas siempre pegada al agua y luego con el cantarillo, siempre a vueltas con el agua como si fueras del agua y no de la tierra; del agua, del aire". Asociación que refuerza el ya mencionado

\footnotetext{
${ }^{10}$ Ibid., p. 53.

${ }^{11}$ Ibid., p. 53.

12 Ibid., p. 56.
} 
oficio de lavandera, el lavado de la roca por el que fluye la sangre de la historia familiar y política, los inferos de la familia y de la polis. Y así se lo hace constar su nodriza: "La historia, niña Antígona, te esperaba a ti, a ti. Por eso estás aquí, tan sola. Por la historia”. ${ }^{13}$ La réplica de Antígona fija admirablemente la acción que inspira la piedad en el oficio de lavandera: “....ahora necesito saber el porqué de tanta monstruosa historia. Contigo me olvidé de estar aquí, y me limpié de todo. Ana, sin tocar tu agua, tú me has lavado. Estoy limpia, limpia. Tú me has lavado. Y ahora necesito lavar"14. A Edipo le había dicho: estoy dispuesta a hacerlos nacer a todos. Ahora, a su nodriza le dice: "necesito lavar". La conciencia-Antígona va ensanchando su ganancia.

Luego viene el fantasma de la madre que acrecienta la conciencia-Antígona despejando el horizonte de su acción: "La sombra de mi madre entró dentro de mí, y yo doncella he sentido el peso de ser madre. Tendré que ir de sombra en sombra, recorriéndolas todas hasta llegar a ti, Luz entera"15. Claro está que ha de recorrer Antígona las sombras como el agua corre y lava; claro está que ha de ser hija y madre virgen, sentirse así para que se cumpla el alumbramiento. Ser madre-mediadora para que se cumpla su particular mayeútica.

Pero a Antígona le estaba reservado ser inspirada por una inspiración contraria, esa que le anima a detenerse ante el terror del poderoso. A dejar la historia cancelada y propagada en forma de mortífera peste. La arpía se cuela en la vivificante tumba de Antígona para impedir que la pesadilla en que se hunde la historia suba a la superficie de la conciencia, pues la arpía es <de las que se deslizan por los laberintos, cuchicheando>. No olvidemos que el cuchicheo es el rumor en que la verdad queda detenida en su infierno. Valga pues este aforismo que improvisamos: El rumor es el infierno de la verdad. El rumor confunde, la arpía dice: "A mí, me temen. A ti, alguien te ama. Es lo mismo". A lo que replica Antígona invocando la nueva ley que profetiza y encarna y sobre todo, desmantelando la envilecida confusión de la harpía: "No, es todo lo contrario. La Ley del Amor es muy distinta de la Ley del Terror y ni siquiera se puede decir que sean todo lo contrario"16. La arpía sale expulsada de la intimidad de Antígona. Las palabras con las que la expulsa invocan la fuerza y el motor de la nueva ley que profetiza Antígona: "Vete, razonadora. Eres Ella, la Diosa de las razones disfrazada. La araña del cerebro. Tejedora de razones vete con ellas. Vete, que la verdad, la verdad de verdad viva tú no la sabrás nunca. $\mathrm{El}$ amor no puede abandonarme porque él me movió siempre, y sin que yo lo buscara. Vino él a mí y me condujo" ${ }^{17}$. La sombra de los hermanos

\footnotetext{
${ }^{13}$ Ibid., p. 58.

${ }^{14}$ Ibid., pp. 58-59.

15 Ibid., p. 63.

${ }^{16}$ Ibid., pp. 65-66.

${ }^{17}$ Ibid., pp. 69-70.
} 
ahonda en el hundimiento familiar y proyecta el triunfo de Creonte. Tebas es ya propiedad de él, el que os venció a los dos y a todos, sin ser por ello victorioso"18. Tomémosle prestada a Marguerite Yourcenar la caracterización última de Creonte, pues "acostado en el lecho de Edipo, descansa sobre la dura almohada de la razón de Estado" ${ }^{19}$. En contraposición, "el péndulo del mundo es el corazón de Antígona"20. Pues en él afloran los frutos, los frutos del sacrificio, su sentido.

Del diálogo con los hermanos y Hemón nace el plano y el alzado de la ciudad prometida, Polinices es su alarife, "fundaremos la ciudad de los hermanos...en ella no hay sacrificio, y el amor, hermana, no está cercado por la muerte. Allí el amor no hay que hacerlo, porque se vive en él. Nadie nace allí, como aquí de este modo. Allí van los ya nacidos, los salvados del nacimiento y de la muerte... uno piensa sin darse cuenta, sin ir de una cosa a otra, de un pensamiento a otro. Todo pasa dentro de un corazón sin tinieblas. Hay claridad porque ninguna luz deslumbra ni acuchilla, como aquí, como ahí fuera"21. Por su parte, Creonte, la persuade para hacerla engranaje de la razón de Estado, reduciéndola al primitivo estado de catástrofe y hundimiento. La pretensión de Creonte es que Antígona se doblegue frente a la voluntad de hierro de la heroína: no traspasar la puerta de la tumba ("esa puerta"), con voluntad de retornar, sometiéndose a la halagadora servidumbre de su razón de Estado, pero no es Antígona espécimen de la servidumbre voluntaria, sirviéndonos del concepto que acuñó magistralmente el barón de la Böetie. Creonte se dirige a ella con voluntad de ganársela: "Como siempre, te adelantas: antes a mi justicia, ahora en mi clemencia. Vengo a sacarte de esta tumba. La muerte de mi hijo, precipitado como tú, me impidió sacarte de aquí a tiempo para que celebrarais vuestras nupcias. Yo quería sólo darte una lección.”22 Antígona se planta en una admirable resistencia que se concreta en un reiterado no. Es de notar que ante Creonte, como ante la arpía, Antígona hace gala de fina ironía y hasta espeta con sarcasmo. No sucede lo mismo en la intimidad de las restantes sombras. Sólo hace Antígona gala de ellos ante aquellos que ostentan el poder y sirven a la Vieja Ley, como Creonte, o ante aquellos que le sirven declaradamente, como la arpía. La persuasión con la que Creonte trata de ganarse a Antígona sacándola de la tumba y convirtiéndola en su cómplice y aliada logra erigir en torno a la doncella un muro sin asedio posible que la hace invulnerable, ya sin temor ni temblor. Pisa un lugar no en la tierra. En contraposición al reino de Creonte: “ya no pertenezco a tu reino", el reino que

\footnotetext{
${ }^{18}$ Ibid. , p. 73.

${ }^{19}$ Yourcenar, M., Fuegos, Trad. Emma Calatayud, Alfaguara, Madrid, 1982, p. 57.

${ }^{20}$ Yourcenar, M., Fuegos, cit., p. 57.

${ }^{21}$ La tumba de Antígona, Mondadori, Madrid, 1989, pp. 79-80.

${ }^{22}$ Ibid., p. 85.
} 
es encrucijada de todas las historias, Antígona muestra su reino en ese más allá indefinible e inapropiable. Ese reino que adivinaba Polinices inasequible para la imaginación, pero diáfano para la iniciación: "Estoy ya entrando en un reino. Voy ya de camino, estoy más allá de donde a un alma humana le es dado el volver". ${ }^{23}$ En esas cimas que ha alcanzado Antígona la comunicación con Creonte se hace imposible. Ante las súplicas del rey por rescatarla de la tumba y devolverla a Tebas como si nada hubiese pasado, Antígona opone el seco escudo del no. Se interpone una Babel entre ellos. "¿Y qué diré a tu hermana que te espera?"-le pregunta Creonte con ánimo desesperado por ablandarla, y le replica Antígona: "Díle, si te acuerdas bien, -no cambies mis palabras- que viva por mí, que viva lo que a mí me fue negado: que sea esposa, madre amor. Que envejezca dulcemente, que muera cuando le llegue la hora, que me sienta llegar con la violeta inmortal, en cada mes de abril, cuando las dos nacimos"24. Naturalmente para Creonte eso son cosas suyas: no te puedo entender, dice en el abismo de su impotencia el poderoso, pero ¿cómo? Si ese sol que sigue Creonte, ya no es el mío-concluye Antígona.

El monólogo final de Antígona es el cumplimiento de su vocación. E1 delirio errático del desvarío con que se abría la obra se ha ido amansando en los sucesivos encuentros, a través de ellos, porque eso es lo propio de Antígona: atender al juego de todos, al juego total, naturalmente, pagando prenda: "Porque la prenda pagada es el inevitable sacrificio que libra de la carga heredada y la genérica. Se paga por ser hijo y por ser simplemente hombre y sólo entonces se abre el camino de la vida individual; sólo a partir de entonces se puede ser uno mismo. Al atender al juego total, como Antígona, se cierra el proceso trágico. El justo que paga abre el camino de la libertad"25 (25). La herencia de Antígona es ese camino. Acaso por ello haya sido tan solicitada en los derrumbes de la historia, porque entonces lo que se invoca es la vida que descubre la maravillosa lámpara de Antígona: la Nueva Ley.

${ }^{23}$ Ibid., p. 86.

${ }^{24}$ Ibid., p. 87.

${ }^{25}$ Zambrano, M., El hombre y lo divino, Méjico, F.C.E., 1986, pp. 224-225. (Nota adicional) Frente a la forma peculiar de M.Zambrano de escribir arpía con hache en el texto de Mondadori, he preferido escribirla sin hache conforme a la ortografía académica. 